\title{
Correlation between the Width of Gallium Oxide Nanobelts and the Diameter of the Catalysts
}

\author{
Woo-Sik Jung \\ School of Displav and Chemical Engineering, College of Engineering, Ieungnam Lniversity, Gyeongsan 71 2-749, Korea \\ E-mail: wsinganacikr \\ Received September 27, 2006
}

Key Words : Gallium oxide. Nanobelts. VLS mechanism, Correlation

One-dimensional (ID) nanostructures such as wires, rods. and belts have been the focus of extensive studies owing to their unique physical properties and potential to revolutionize broad areas of nanoteclunology. ${ }^{1}$ Various synthetic techniques have been used to grow ID nanostructures via the vaporliquid-solid (VLS) mechanism, ${ }^{2}$ which was proposed by Wagner and Ellis. ${ }^{3}$ The characteristic features of this mechanism are that the ID nanostructures have metal or alloy droplets at their tips which act as catalysts and these droplets define their diameters, i.e. smaller catalyst droplets yield thinner ID nanostructures. Very recently some theoretical models have been suggested on the effect of the droplet size on the growth kinetics of nanowires by the VLS mechanism. ${ }^{+}$However, the effect of the diameter $\left(d_{c a f}\right)$ of the catalyst droplets on the dianeter $\left(d_{\text {ramo }}\right)$ of the ID nanostructures remains little understood theoretically. There have only been a few reports which show an empirical correlation between $d_{\text {mano }}$ and $d_{c a r .}{ }^{5.7}$ Another goal of current theoretical investigations is to fund out the main factor which determines the ratio of $d_{\text {nomo }}$ to $d_{\text {car }}$. For example, in most cases, the $d_{\text {nuro }}$ value of the nanowires was found to be greater than the initial $d_{c a t}$ value of the catalyst prior to their growth. $^{7.11}$ On the other hand. the $d_{\text {nom }}$ value of GaAs nanowires. which were formed by the solution-liquid-solid mechanisnt. was ca. $60 \%$ of the initial $d_{\text {cat }}$ value. ${ }^{\circ}$

In this conmunication, we report the synthesis of a monoclinic $\beta-\mathrm{Ga}_{2} \mathrm{O}_{3}$ nanobelts via the reduction of $\mathrm{Ga}_{2} \mathrm{O}_{3}$ by $\mathrm{CO}$ and subsequent oxidation and show an empirical corre- lation between the $d_{\text {nan }}$ value of the namobelts and the $d_{c a t}$ value. $\beta-\mathrm{Ga}_{2} \mathrm{O}_{3}$ powder (Wako Pure Chemical Industries, Ltd., 99.99\%) was loaded in an alumina crucible and a (100) silicon substrate was placed at the downstream end of the crucible at a distance of $200-250 \mathrm{~mm}$ from the $\mathrm{Ga}_{2} \mathrm{O}_{3}$ source. The alumina crucible was heated at $1200^{\circ} \mathrm{C}$ in a mixed gas flow $(90 \%$ nitrogen and $10 \% \mathrm{CO}$ ) for $2 \mathrm{~h}$. After cooling the furnace to room temperature. the as-deposited products on the surface of the substrate were wool-like with a light gray color. The XRD pattern of the products revealed that they are assigned to a crystalline monoclinic $\beta$-Ga $\mathrm{G}_{3}$ (JCPDS Card No. 4l-1103).

The morphology of the $\beta \mathrm{Ga}_{2} \mathrm{O}_{3}$ was influenced by the substrate temperature. The product deposited on the substrate at ca. $720^{\circ} \mathrm{C}$ is demonstrated in Figure $\mathrm{l}$ (a), in which there are lots of nanobelts having droplets at their tips. As shown in Figure 1(b). a typical nanobelt in the prodcuct terminates in a droplet at its tip. Energy-dispersive X-ray spectroscopy measurements made on the droplet and the belt indicated that the droplet is composed mainly of $\mathrm{Ga}$, while the belt is composed of $\mathrm{Ga}$ and oxygen. The presence of the Ga droplet at the nanobelt tip in Figure 1 provides strong evidence that the nanobelt grows via the VLS mechanism. $\beta$ $\mathrm{Ga}_{2} \mathrm{O}_{3}$ powder in a hot zone will be reduced first to $\mathrm{Ga}_{2} \mathrm{O}(\mathrm{g})$ and then to $\mathrm{Ga}(\mathrm{g})$ by $\mathrm{CO}$. As gaseous $\mathrm{Ga}$ travels in the gas strean to cooler zones in the furnace. it will be oxidized to $\mathrm{Ga}_{2} \mathrm{O}_{3}(\mathrm{~g})$ by $\mathrm{O}_{2}$. The $\mathrm{Ga}_{2} \mathrm{O}_{3}(\mathrm{~g})$ diffuses into the unoxidized $\mathrm{Ga}$ droplets on the Si substrate. and then is supersaturated
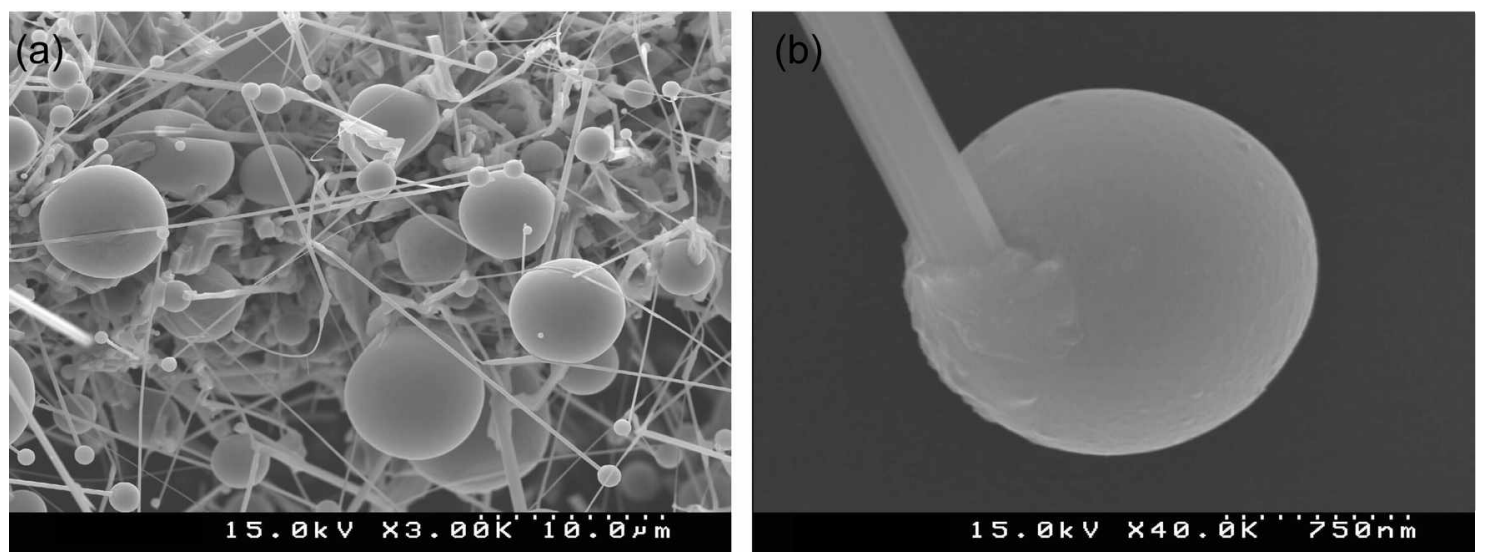

Figure 1. (a) SEM inage of the as-synthesized products obtained from the reduction of $\beta \mathrm{Ga}_{2} \mathrm{O}_{3}$ by $\mathrm{CO}$ and subsequent oxidation. (b) $\mathrm{A}$ typical SEM image of a $\beta \mathrm{Ga}_{2} \mathrm{O}_{3}$ nanobelt carrying a $\mathrm{Ga}$ droplet at its tip. 
and nucleated in the droplets. Continuous diffusion causes $\mathrm{Ga}_{2} \mathrm{O}_{3}$ nanobelts to grow out of the droplet, as shown in Figure 1(b). The $\mathrm{Ga}_{2} \mathrm{O}_{3}$ nanobelts were obtained in a flowing gas mixture of nitrogen and $\mathrm{CO}$ without any intentional supply of $\mathrm{O}_{2}$. Therefore. the residue oxygen in the mixed gas is believed to be the source of oxygen for the growth of the nanostructures. The formation of Ga droplets indicates that the amount of the residue oxygen was not sufficient to oxidize all of the Ga vapor formed. Fu et al. synthesized $\beta$ $\mathrm{Ga}_{2} \mathrm{O}_{3}$ nanobelts via the reduction of $\mathrm{Ga}_{2} \mathrm{O}_{3}$ by $\mathrm{H}_{2}$ and subsequent oxidation at $1000^{\circ} \mathrm{C}$ but did not observe any $\mathrm{Ga}$ droplets at the nanobelt tips. "They surmised that the Ga droplets might be reduced during the growth periods at the high temperature $\left(900^{\circ} \mathrm{C}\right)$ of the deposition site because of the low melting point $\left(29.8^{\circ} \mathrm{C}\right)$ of Ga metal.

As shown in Figure 1(a). the Ga droplets at the nanobelt tip were inhomogeneous and relatively large (above 500 num). The analysis by SEM revealed that the width $\left(w^{\prime} b_{0}\right.$ t $)$ of the $\beta-\mathrm{Ga}_{2} \mathrm{O}_{3}$ nanobelts depends on the $d_{c a t}$ value of the $\mathrm{Ga}$ droplets. Figure 2 shows that there is a linear correlation between $w^{*}$ eert and $d_{c a t}$. The data in Figure 2 were taken from the spherical $\mathrm{Ga}$ droplets. The equation of the correlation line was obtained through linear regression analysis and is as follows:

$$
w_{\text {belf }}(\mathrm{nm})=(0.21 \pm 0.01) d_{\text {cut }}(\mathrm{nm})+(5.3 \pm 16)
$$

where the errors shown correspond to the standard deviations. The slope of the correlation line means that the Whert value is $c a .20 \%$ of the $d_{c a t}$ value. This contrasts with the results obtained for the growth of $\beta \mathrm{Ga}_{2} \mathrm{O}_{3}$ nanobelts by the Sn-catalyzed VLS mechanism. in which the $d_{c a t}$ value of the Sn particles was much smaller than the $w^{\prime}$ belf value of the nanobelt and was the same as the thickness of the nanobelt. ${ }^{12}$ This difference might be explained in ternts of the solubility of the growth vapor in the catalyst droplets. The solubility' is expected to increase with increasing temperature gap between the melting point of the catalyst and the growth temperature. i.e. the solubility of $\mathrm{Ga}_{2} \mathrm{O}_{3}$ vapor will be much higher in the Ga droplets than in the Sn droplets higher at the same temperature because the melting point of $\mathrm{Ga}$ is much lower than that of Sn. This higher solubility will cause the initial size of the cataly'st droplets to be increased i.e.. the increase in the size will be larger for the Ga droplets than for the Sn droplets. In addition. the degree of the increase will be a function of the reaction temperature.

Besides the size of the catalyst. the growth temperature also has an effect on the size of the ID nanostructures. For example. Chang and Wu sy'nthesized $\beta-\mathrm{Ga}_{2} \mathrm{O}_{3}$ nanowires on All-coated Si substrates by evaporating $\mathrm{Ga}$ (acetylacetonate) and found that there was no significant distinction between the average size of the Au particles formed at 850 and 550 ${ }^{\circ} \mathrm{C}$, whereas the diameters of the nanowires increased by a factor of 2 over this temperature range. ${ }^{13}$ Recently we showed that the grow th temperature influenced the thickness of aluminum nitride (AlN) whiskers which were grown via the Fe-catalyzed VLS mechanism. i.e. a higher growth

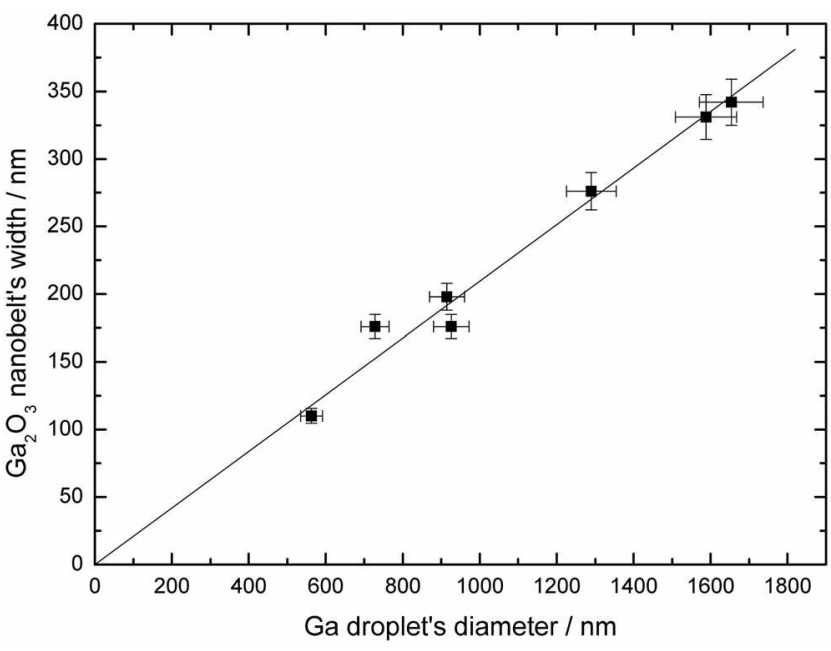

Figure 2. Correlation between the width of the $\beta-\mathrm{G}_{2} \mathrm{O}_{3}$ nanobelts and the diameter of the Ga droplets.

temperature yielded thicker AIN whiskers. ${ }^{1+}$ Therefore, the temperature should be considered when analyzing the ratio of $d_{\text {rano }}$ (or $w_{\text {iplit) }}$ to $d_{\text {cat }}$. More detailed studies are in progress in order to elucidate the effects of the catalyst and temperature on the ratio of whell to $d_{c a t}$ in the growth of $\beta-\mathrm{Ga}_{2} \mathrm{O}_{3}$ nanobelts.

In conclusion, $\beta-\mathrm{Ga}_{2} \mathrm{O}_{3}$ nanobelts were prepared by the thermal evaporation of $\beta \mathrm{Ga}_{2} \mathrm{O}_{3}$ in a flowing gas mixture of nitrogen and $\mathrm{CO}$ without using any catalyst. The nanobelts were deposited on a Si substrate via the VLS mechanism. The $w^{\prime} b_{\text {esh }}$ value of the nanobelts was linearly correlated with the $d_{c a t}$ value of the Ga droplets. suggesting that the width of the $\beta-\mathrm{Ga}_{2} \mathrm{O}_{3}$ nanobelts could be controlled by adjusting the size of the Ga droplets.

Acknowledgements. This work was supported by National Center for Nanomaterials Teclunology.

\section{References}

1. Hu. J.: Odom. T. W. Lieber. C. M. Acc. Chem Res. 1999, 32.435

2. Xia. Y: Yang, P.: Sun. Y: Wu. Y: Mayers. B.: Gates, B: Yn. Y: Kim. F.: Yan. H. $A$ d : Mater: $2003,15,353$

3. Wagner. R. S.: Ellis, W. C. Appl. Phys. Lett 1964. 4.89.

4. Chent. Z.: Cao. C. Appl Phs Lent 2006. 88. 143118: Kashchiev. D. Crustal Growth \& Design 2006. 6. 1154.

5. Wang. C.-X.: Wang. B.: Yang. Y.-H.: Yang. G.W. J. Phns. Chen B 2005. 109.9966 .

6. Yu. H.: Buhro, W. E. Ad. Hater: 2003. 15. 416.

7. Wu, Y: Yang, P. J. Am. Chem. Soc. 2001. 123.3165

8. Gudiken. M. S.: Lieber. C. M. J. An. Chem. Soc. 2000.122 .8801

9. Gudiken. M. S.: Wang. T.: Lieber. C. M. J. Phrs. Chem. B 2001. 105. 4062 .

10. Cui. Y.: Lauhon. L. J.; Gudiken, M. S.; Wang, J; Lieber, C. M. Appl. Phis. Lett. 2001. 78, 2214

11. Fu. L.; Liu, Y.: Hu, P.: Xiao. K; Yu. G; Zhu. D. Chem Maten: 2003. 15.4287

12. Zhang. J.: Tiang. F.: Yang. Y.: Li. T. J. Phus. Chent. B 2005. 109. 13143.

13. Chang. K.-W.: Wu, J.J. J. Phus. Chem. B 2004. 108, 1838.

14. Jung. W.-S.: Joo. H. U. J. Crystal Growth 2005, 285, 566. 